\title{
Symulacja numeryczna wpływu zmian warunków technologicznych na rozkład naprężeń i odkształceń wymiennika ciepła
}

\author{
Numerical Simulation of technological conditions influence \\ on stress and distortion distribution in heat exchanger
}

\section{Streszczenie}

W artykule tym przestawiono wpływ kolejności spawania oraz temperatury podgrzania wstępnego na rozkład naprężeń i odkształceń $\mathrm{w}$ modelowym elemencie rurowego wymiennika ciepła. Analizie poddano wpływ kolejności spawania oraz podgrzewania wstępnego elementów płyty sitowej z rurami wymiennika. Do symulacji użyto oprogramowania SYSWELD grupy ESI Group, pozwalającego na nieliniowa analizę zjawisk termicznych, mechanicznych i metalurgicznych występujących w procesie spawania z wykorzystaniem metody elementów skończonych.

Słowa kluczowe: analizy numeryczne; MES; SYSWELD; naprężenia spawalnicze; odkształcenia spawalnicze

\begin{abstract}
In this article influence of welding order and preheating on stress and distortion distribution in showcase element of shell and tube heat exchanger is presented. Welding sequence and preheating influence on tube sheet - tubes joints was analyzed. Simulations were conducted with SYSWELD software from ESI Group. This software allows nonlinear analysis of thermal, mechanical and metallurgical phenomena during welding with use of finite element method.
\end{abstract}

Keywords: numerical analysis; FEM; SYSWELD; welding stresses; welding distortions

\section{Wstęp}

Procesy spawalnicze są prawdopodobnie najbardziej rozpowrzechnionymi dzisiaj metodami łączenia materiałów. Jednak użycie spawalniczych źródeł ciepła powoduje zmiany w strukturze, naprężeniach i odkształceniach elementów łączonych powodujące szereg niedogodności.

Nadmierne odkształcenie konstrukcji może utrudniać montaż konćowy, a także gdy przekroczone zostaną poziomy akceptacji powoduje konieczność wykonania dodatkowych operacji technologicznych. Operacje prostowania generują dodatkowe koszty oraz wydłużają czas produkcji. Naprężenia własne tworzą zrównoważony system sił wewnętrznych wystepujący także w przypadku braku sił zewnętrznych. Rozkład naprężeń wewnętrznych ma wpływ na wytrzymałość konstrukcji oraz jej trwałość. Analiza pól naprężeń pozwala na zlokalizowanie regionów w których tworzyć mogą się pęknięcia, a także przewidywać bezpieczny czas pracy konstrukcji poddanych obciążeniom zmiennym. Na występowanie odkształceń konstrukcji i naprężeń własnych wpływa skomplikowany system czynnikików materiałowych, technologicznych i konstrukcyjnych. Nieliniowy wpływ czynników takich jak: własności mechaniczne materiału, przemiany metalurgiczne, rodzaj i parametry technologii spawania, kolejność wykonania spoin, sposób mocowania elementów, postać geometryczna konstrukcji i jej wymiary powoduje znaczne utrudnienia w przewidywaniu wartości naprężeń i odkształceń. [1,2]
Symulacje numeryczne pozwalają na predykcje efektów zastosowania spawalniczych metod łączenia materiału, już na etapie projektowania konstrukcji. Symulacje te pozwalają także na optymalizację już istniejącej technologii w celu poprawy trwałości konstrukcji. Użycie oprogramowania do symulacji numerycznych pozwala zmniejszyć ilość prototypów, a co za tym idzie zmniejszyć koszty i czas związany z opracowaniem konstrukcji spawanej. Symulacje metodą elementów skończonych z wykorzystaniem oprogramowania SYSWELD pozwalają na analizę: [2]

- rozkładu pól temperatur,

- rozkładu występowania poszczególnych faz metalurgicznych (dla stali zawartość: martenzytu, bainitu, ferrytu i perlitu oraz austenitu),

- rozkładu twardości,

- odkształceń konstrukcji,

- rokładu naprężeń,

- degradacji materiału,

- prognozowanej granicy plastyczności.

W pracy tej wykorzystano metodę analizy ciągłej (transient welding). Polega ona na numerycznej analizie zjawisk w czasie poruszania się źródła ciepła wzdłuż wyznaczonego toru. Obliczenia wykonywane są dla każdej chwili czasowej. Chwile czasowe są odległe od siebie o krok czasowy, który w celu uzyskania prawidłowych wyników dla analizy termo-metalurgicznej wynosi maksymalnie pół długości jeziorka ciekłego metalu, a dla analizy mechanicznej maksymalnie długość

Mgr inż. Bernard Wyględacz, dr inż. Tomasz Kik - Politechnika Śląska.

Autor korespondencyjny/Corresponding author. bernard.wygledacz@pols.pl 
jeziorka. Analiza numeryczna podzielona jest na dwie części: Obliczenia zjawisk termicznych i metalurgicznych oraz obliczenia mechaniczne. W pierwszej kolejności wykonywane są obliczenia termiczne i metalurgiczne jako wzajemnie zależne. Następnie wynik tych obliczeń w postaci rozkładu faz metalurgicznych, przemian i pól temperatur w czasie procesu stanowią historię dla obliczeń mechanicznych $[1,3]$.

W celu zaprezentowania możliwości oprogramowania wykonany został model połączenia rur wymiennika ciepła z płytą sitową. Element ten wybrano jako przykład, w którym na końcowe parametry konstrukcji wpływa wielokrotne oddziaływanie cykli cieplnych wynikające ze spawania poszczególnych spoin.

\section{Przebieg symulacji}

W celu dokonania analiz MES w programie SYSWELD wykonano model składający się z płyty sitowej o średnicy $150 \mathrm{~mm}$ i grubości $7 \mathrm{~mm}$ oraz 12 rur o średnicy $10 \mathrm{~mm}$ grubości ścianki $2 \mathrm{~mm}$ i długości $85 \mathrm{~mm}$ i ich spoin (wymiar a=1,5mm) rozmieszczonych równomiernie na obwodzie płyty. Siatka elementów skończonych składa się z 46440 elementów trójwymiarowych typu solid oraz 62770 węzłów i widoczna jest na rysunku 1. Na rysunku tym naniesiono także sposób numercji kolejnych rur. W celu usystematyzowania prezentacji wyników widok widoczny na rysunku 1 został zachowany na wszystkich mapach barwnych przedstawiających wyniki.

Modelowi nadano własności stali ASTM A 516 Grade 70. Skład chemiczny materiału tworzącego bazę materiałową podano w tablicy I. Jako metodę wykonania złącza wybrano 141, symulowaną za pomocą źródła ciepła w kształcie podwójnej elipsoidy (źródło Goldaka). Następnie przeprowadzono dopasowanie źródła ciepła do spawanego złącza czego wynikiem były następujące parametry: wymiary źródła 4,5/4,5/1,75 mm, prędkość spawania $2 \mathrm{~mm} / \mathrm{s}$, energia liniowa spawania $690 \mathrm{~J} /$ $\mathrm{mm}$. W celu utrzymania jednakowego wtopienia użyto rampy początkowej i końcowej. Rozkład temperatury na przekroju spawanego złącza pokazano na rysunku 2. Model usztywniono mocując rury na ich górnych końcach oraz luźno umieszczając płytę sitową. 2000 s po rozpoczęciu spawania rury są uwalniane z ograniczeń. Jako termiczne warunki brzegowe ustalono wymianę ciepła z powietrzem o temperaturze $20^{\circ} \mathrm{C}[4,5]$.

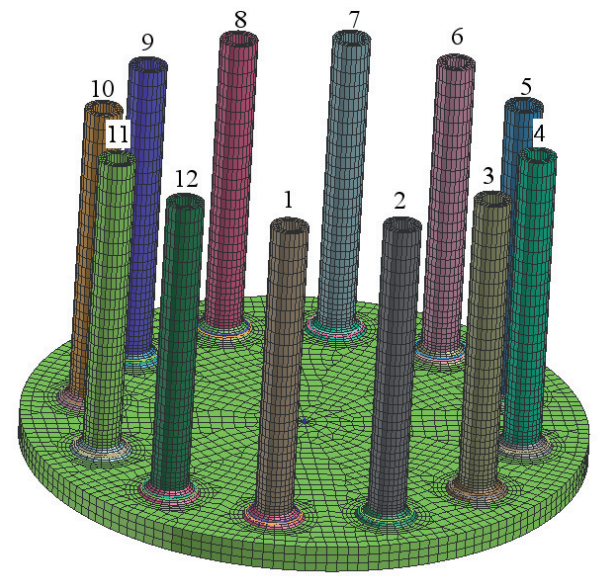

Rys. 1. Symulowany model wraz z naniesioną numeracją rur Fig. 1. Simulated model with pipe numeration included

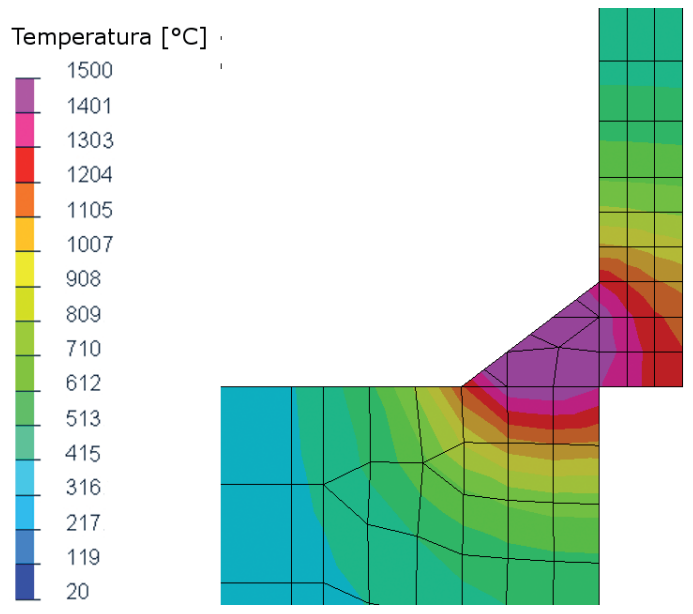

Rys. 2. Symulowany model wraz z naniesioną numeracją rur Fig. 2. Simulated model with pipe numeration included

Jako parametry zmienne w technologi wybrano kolejność wykonania spoin oraz temperaturę podgrzewania wstępnego. Dla każdego z tych parametrów wybrano dwie wartości do symulacji co dało łącznie 4 warianty. Kolejności spawania jakie zastosowano to spawanie kolejnych spoin przeciwnie do kierunku wskazówek zegara $(1,2 \ldots 11,12)$ oraz spawanie naprzemiennie leżących spoin także w kierunku przeciwnym do wskazówek zegara $(1,7 \ldots 6,12)$. W połowie przypadków zastosowano brak podgrzewania, a w drugiej połowie podgrzewanie wstępne do $150^{\circ} \mathrm{C}$.

Model poddano analizie ciągłej (transient welding), jako dane wejściowe stosując model elementu oraz podane parametry technologii. Wykonano analizę termo-metalurgiczną oraz analizę mechaniczną dla każdego z badanych przypadków. [4]

\section{Wyniki oraz analiza}

W wyniku post-processingu uzyskano mapy barwne przedstawiające rozkład naprężeń i odkształceń w kontrukcji. Na rysunku 3 przedstawiono rozkład naprężeń przed uwolnieniem elementu z symulowanego przyrządu, a na rysunku 4 po uwolnieniu. Mapy barwne wykonano także dla rozkładu naprężeń dla sytuacji przed uwolnieniem i po uwolnieniu. Zamieszczono je na rysunkach 5 oraz 6 .

Naprężenia w konstrukcji wykazują podobny rozkład niezależnie od kolejności spawania. Podgrzewanie wstępne powoduje zmniejszenie maksymalnych naprężeń końcowych w konstrukcji oraz zwiększenie naprężeń maksymalnych przed uwolnieniem bez większego wpływu na ich rozkład. Zwiększenie naprężeń spowodowane może być poprzez nałożenie więzów na elementy rozgrzane do $150{ }^{\circ} \mathrm{C}$ W rurach przed uwolnieniem występują naprężenia dochodzące miejscami do $200 \mathrm{MPa}$. Po uwolnieniu naprężenia w rurach występują tylko $w$ bezpośrednim sąsiedztwie złącza spawanego. Maksymalne naprężenia w konstrukcji spadają nieznacznie po jej uwolnieniu. W płycie pola naprężeń o wartość powyżej 300 MPa występuja w okolicach poszczególnych spoin. Wpływa na to swobodny charakter mechanicznych warunków brzegowych narzuconych płycie.

Tablica I. Skład chemiczny stali w bazie materiałowej ASTM A 516 Grade 70

Table I. Chemical composition of steel in material database ASTM A 516 grade 70

\begin{tabular}{|c|c|c|c|c|c|c|c|}
\hline \multicolumn{10}{|c|}{ Skład chemiczny [\% wag.] } \\
\hline C & Mn & $\mathrm{Si}$ & $\mathrm{Cr}$ & $\mathrm{Ni}$ & $\mathrm{Cu}$ & $\mathrm{S}$ & $\mathrm{P}$ \\
\hline 0,22 & 1,2 & 0,45 & 0 & 0 & 0 & 0,035 & 0,035 \\
\hline
\end{tabular}




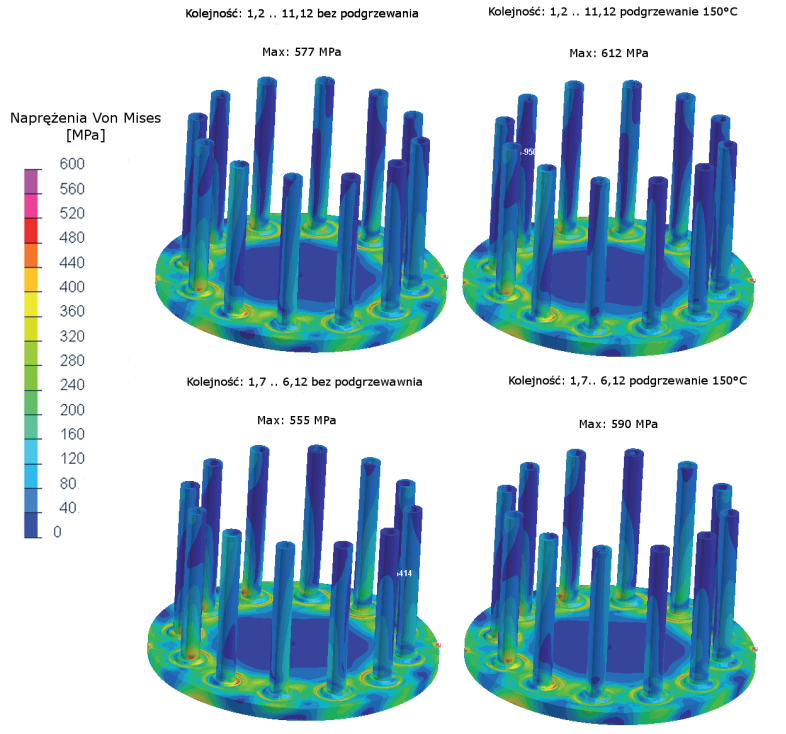

Rys. 3. Mapy barwne rozkładu naprężeń przed uwolnieniem z zamocowania

Fig. 3. Color map of stress distribution before removal from clamping

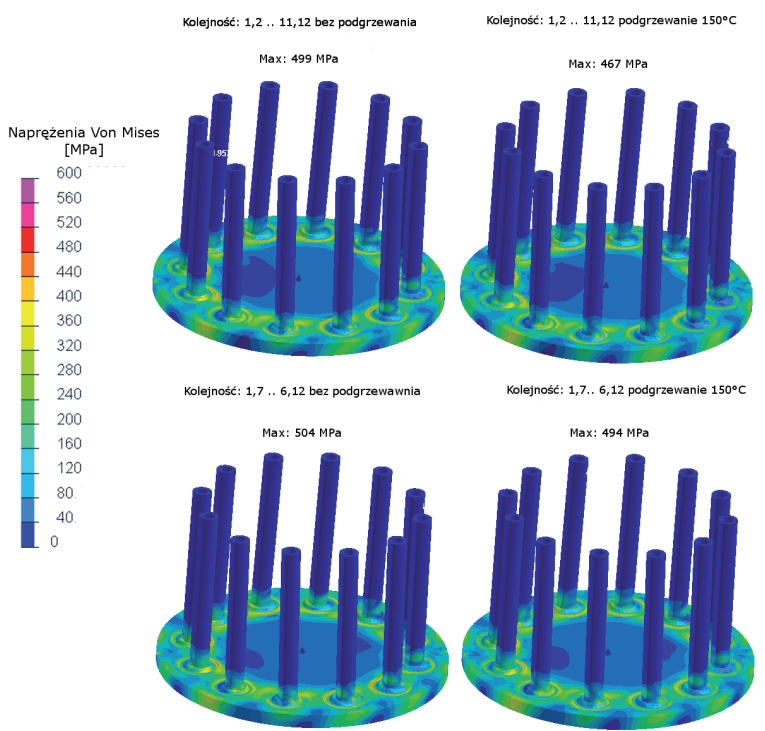

Rys. 4. Mapy barwne rozkładu naprężeń po uwolnieniu z zamocowania Fig. 4. Color map of stress distribution after removal from clamping

Odkształcenia konstrukcji przed uwolnieniem skoncentrowane są w płycie i wynoszą do około $0.3 \mathrm{~mm}$ we wszystkich przypadkach. Po uwolnieniu natomiast odkształcenia zdecydowanie rosną i skoncentrowane są $w$ rurach. Związane jest to z uwolnieniem konstrukcji spod działania sił zewnętrznych, w momencie zdjęcia mechanicznych warunków brzegowych symulujących przyrząd. Odkształcenia maksymalne, ich kierunek oraz rozkład zależą od kolejności spawania. Odkształcenia maksymalne przy pierwszym wariancie kolejności spawania występują w rurze 7, a przy drugiej symulowanej kolejności spawania wartość maksymalna

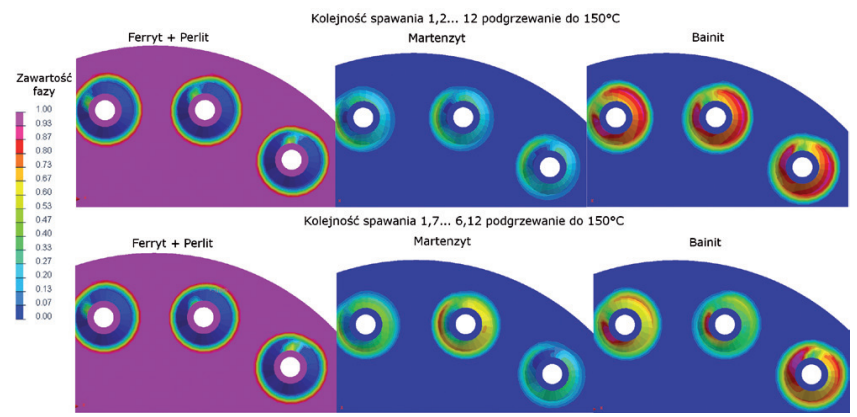

Rys. 7. Rozkład faz metalurgicznych na powierzchni złączy $6,7,8$ Fig. 7. Metallurgical phases distribution on joint $6,7,8$ surface

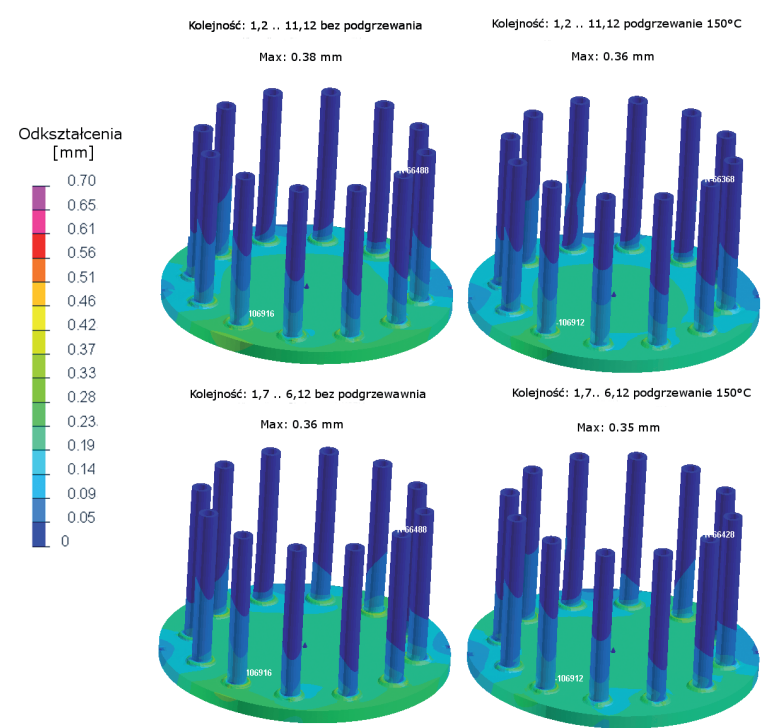

Rys. 5. Mapy barwne odkształceń przed uwolnieniem z zamocowania

Fig. 5. Color map of distortion before removal from clamping

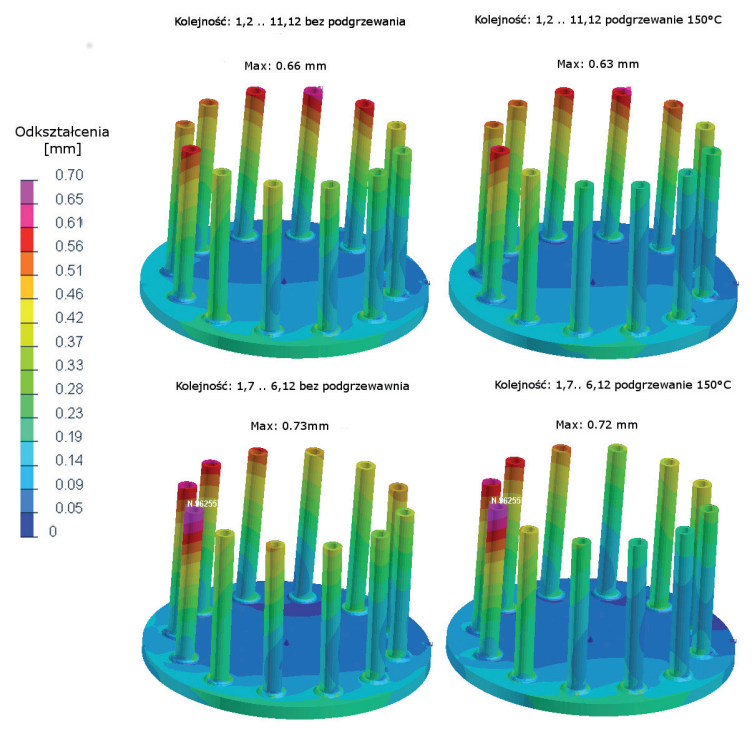

Rys. 6. Mapy barwne odkształceń po uwolnieniu z zamocowania Fig. 6. Color map of distortion after removal from clamping

odkształcenia wystąpiła w rurze 11. Natomiast zastosowanie podgrzewania wstępnego powoduje nieznaczne zmniejszenie odkształceń, nie wpływając jednocześnie na ich rozkład.

Na rysunku 7 przedstawiono rozkład faz metalurgicznych na powierzchni złącza 6,7,8 dla obu kolejności spawania

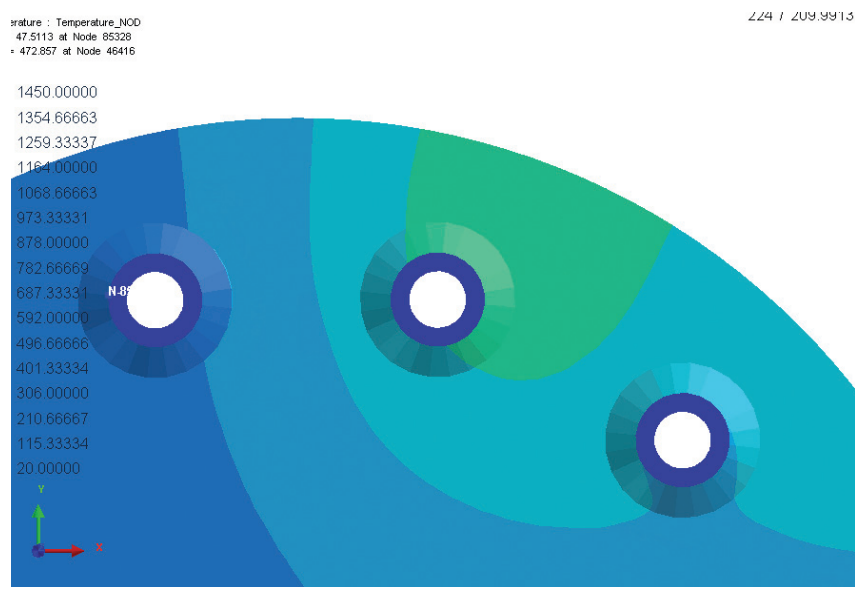

Rys. 8. Rozkład pól temperatur po zakończeniu spawania 7 złącza przy kolejności spawania 1,2... 12

Fig. 8. Temperature fields distribution after welding joint 7 with welding sequence $1,2 \ldots 12$ 
przy podgrzewaniu wstępnym do $150^{\circ} \mathrm{C}$. Na korzystniejszy rozkład faz metalurgiczny przy kolejności spawania rur $1,2 \ldots$ 12 wpływa pokrywanie się pól zwiększonej temperatury spowodowanych spawaniem wcześniejszej spoiny z okolicami kolejnego złącza spawanego co widoczne jest na rysunku 8. W wyniku tego prędkość chłodzenia jest mniejsza, a co za tym idzie dyfuzja zachodzi w większym zakresie powodując powstanie zwiększonych ilości bainitu w miejsce martenzytu. W przypadku kolejności spawania 1,7 ... 6,12 występuje także duża różnorodność w rozkładzie faz metalurgicznych pomiędzy złączami co powodować może rozrzut jakości złączy.

\section{Wnioski}

Po wykonaniu analizy wyników wysunięto następujące wnioski:

- Jako najlepszą technologię wybrano spawanie złączy w kolejności 1,2... 12 z zastosowaniem podgrzewania, jako powodującą najmniejsze naprężenia i odkształcenia oraz w której występował podobny rozkład faz metalurgicznych we wszystkich spoinach. W tym wariancie technologii fazą metalurgiczną o największym udziale w złączach spawanych był bainit. Mniejsze zahartowanie struktury korzystnie wpływa na naprężenia maksymalne oraz możliwość zarodkowania i rozwoju pęknięć w złączu.

- Wpływ podgrzewania wstępnego na zmniejszenie odkształceń i naprężeń własnych był niewielki i jeżeli podgrzewanie nie jest koniecznym warunkiem technologii można je pominąć jako dodatkowy zabieg generujący koszty.

- Na wynikową strukturę metalurgiczną wpływa nie tylko temperatura podgrzewania i dostarczone ciepło ale także, pośrednio poprzez wzajemne odziaływanie cykli cieplnych, kolejność spawania.

\section{Literatura}

[1] M. Slováček, T. Kik: Wykorzystanie analiz numerycznych procesów spawania jako wsparcia technicznego w przemyśle. Cz. 1, Wstęp do zagadnienia symulacji numerycznych procesów spawania.; Biul. Inst. Spaw. Gliwice 2015 R. 59 nr 4.

[2] M. Slováček, T. Kik: Wykorzystanie wirtualnych symulacji numerycznych procesów spawania w sektorze energetycznym; Bloki o nadkrytycznych parametrach pracy, Bełchatów 2015
[3] Goldak J.A., Oddy A., Gu M., Ma W., Mashaie A., Hughes E: Coupling heat transfer, microstructure evolution and thermal stress analysis in weld mechanics; IUTAM Symposium. Mechanical Effects of Welding, Lulea Sweden.

[4] M. Slováček, T. Kik: Wykorzystanie analiz numerycznych procesów spawania jako wsparcia technicznego w przemyśle. Cz. 2, metodologia i walidacja.; Biul. Inst. Spaw. Gliwice 2015 R. 59 nr 5.

[5] ESI Group: SYSWELD reference manual, digital version SYSWELD 2015.2. 